\title{
Os custos eleitorais do Bolsa Família: reavaliando seu impacto sobre a eleição presidencial de 2006
}

Diego Sanches Corrêa

\section{Introdução ${ }^{1}$}

Desde o fim da ditadura militar, o Brasil realizou sete eleições presidenciais e teve chefes de governo de quatro partidos diferentes. O candidato do partido governista ganhou ou disputou o segundo turno nas cinco últimas eleições (1998, 2002, 2006, 2010 e 2014), mas em nenhuma delas o padrão geográfico de suas flutuações eleitorais foi tão surpreendente quanto aquele observado entre 2002 e 2006. Esse fenômeno tem sido objeto de diversos estudos recentes utilizando diferentes metodologias de análise e abordagens interpretativas (Hunter e Power, 2007; Licio, Rennó e Castro, 2009; Marques et al., 2009; Nicolau e Peixoto, 2007; Shikida et al., 2009; Singer, 2009; Soares e Terron, 2008; Zucco, 2008, 2013). Na maioria das vezes, o foco se restringiu à associação negativa entre o nível de desenvolvimento municipal ou o status socioeconômico do indivíduo e o apoio eleitoral a Lula.

Uma das explicações comumente propostas pela literatura enfatiza a influência do Bolsa Família, um grande programa de transferência de renda condicionada (TRC) implementado por Lula em 2003. Ao final de 2006, o programa já cobria cerca de $19 \%$ da população brasileira, mas a taxa de cobertura variava enormemente entre os municípios do país. Nicolau e Peixoto (2007) notaram uma alta correlação entre a cobertura do programa e a votação de Lula no nível municipal, o que os levou a argumentar que o Bolsa Família teve papel determinante em seu desempenho eleitoral. De acordo com eles, "cada 100 reais de aumento per capita do Bolsa Família traz um aumento de três pontos percentuais na votação de Lula nos municípios" (Nicolau e Peixoto, 2007, p. 23). Esse estudo foi pioneiro no debate que se iniciou logo após a eleição presidencial de 2006 e recebeu algumas críticas (ver Shikida et al., 2009), mas a maioria dos estudos subsequentes confirmaram e expandiram os seus achados.

Nos anos seguintes, a tese de que investimentos no Bolsa Família explicam em alguma medida o desempenho eleitoral de Lula em 2006 tornou-se quase um consenso entre os estudiosos das eleições brasileiras. Hunter e Power (2007) mostraram que o programa não está apenas associado com a votação de Lula em 2006, mas também com a flutuação de seu apoio eleitoral entre 2002 e 2006 e com o aumento do

\footnotetext{
1 "Agradeço a José Cheibub, Rodolfo Hoffmann, Fernando Limongi, Milan Svolik, Timothy Power e Matthew Winters, além de três pareceristas anônimos, pelas excelentes sugestões. Versões anteriores deste artigo foram apresentadas no encontro da Associação Brasileira de Ciência Política de 2010 e no "Workshop on Political Consequences of Declining Inequality in Brazil" na Universidade de Oxford em 2010. Todos os eventuais problemas e erros são de minha inteira responsabilidade.
} 
comparecimento nas áreas menos desenvolvidas do país. Esses achados levaram os autores a associar o programa à vitória eleitoral de Lula e a argumentar que "a história da política social é provavelmente a explicação mais plausível para a reeleição de Lula" (Hunter e Power, 2007, p. 20). Sustentando essa interpretação, Soares e Terron (2008, p. 298) conjecturam sobre o impacto eleitoral do Bolsa Família e afirmam que "o esforço de 2006 , cerca de $0,35 \%$ do PIB e $0,9 \%$ do gasto público, se reverteu em êxito eleitoral e expansão das bases geoeleitorais de Lula". Alguns anos depois, analisando o impacto de programas de TRC em três pleitos eleitorais (Bolsa Escola em 2002 e Bolsa Família em 2006 e 2010), Zucco (2013) sublinhou seu potencial para beneficiar candidatos governistas de partidos diferentes. De acordo com o autor, "programas de TRC influenciaram as eleições brasileiras mesmo antes de eles chamarem a atenção de analistas e em tempos de bom e mau desempenho econômico" (Zucco, 2013, p. 820). O argumento de que investimentos em programas sociais geram ganhos eleitorais para o candidato governista é também popular na imprensa e sua atratividade o tem feito voltar à tona também em eleições posteriores à de $2006^{2}$. Logo após as eleições presidenciais de 2010, por exemplo, um dos jornais de maior circulação no Brasil publicou um par de mapas em que a votação municipal da candidata do PT Dilma Rousseff visivelmente refletia o mapa da cobertura do Bolsa Família, sugerindo uma forte associação entre os dois ${ }^{3}$.

O que tem sido negligenciado por essa literatura é que o programa recebeu uma quantidade expressiva de cobertura midiática negativa, foi rotineiramente criticado pela oposição e também pode ter levado Lula a perder votos entre membros das classes mais abastadas. Apesar de os candidatos presidenciais do principal partido de oposição, o PSDB, prometerem manter o Bolsa Família durante as campanhas eleitorais de 2006 e 2010, alguns de seus correligionários não hesitaram em fazer declarações negativas sobre o programa. É notável, por exemplo, que a própria esposa de José Serra, o candidato do PSDB na eleição de 2010, se referisse ao programa dizendo que "as pessoas não querem mais trabalhar, não querem assinar carteira e estão ensinando isso para os filhos", durante um evento de campanha na cidade de Curitiba (PR) ${ }^{4}$. Algumas semanas depois, Tasso Jereissati, então presidente do PSDB, declarou num evento de campanha em Tianguá (CE): "Vai acabar todo mundo no Bolsa Família e ninguém produz mais nada. Isso é uma grande enganação que está se plantando para o povo brasileiro e

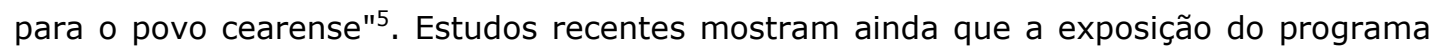

\footnotetext{
${ }^{2}$ Veja, por exemplo, os artigos "Bolsa Família rendeu a Lula 2,9 milhões de votos" em O Globo, 24 jul. 2009, "Bolsa-Cabresto" em Veja (edição 2.149, 27 jan. 2010), "Bolsa Família é paraquedas eleitoral de Dilma no Norte/Nordeste" em O Estado de S. Paulo, 11 out. 2010, e "Bolsa Família alimentou votos em Dilma" em O Globo, 16 out. 2010.

3 "Votação de Dilma cresce de acordo com alcance do Bolsa Família, indica estudo", O Estado de S. Paulo, 6 out. 2010.

4 "Mônica Serra corrige crítica ao Bolsa Família", Valor Econômico, 23 ago. 2010.

5 "Tasso diz que Bolsa Família é uma 'grande enganação'", O Estado de S. Paulo, 6 set. 2010.
} 
na mídia brasileira é alta e que visões negativas são veiculadas com bastante frequência (Biroli e Mantovani, 2010; Marques, 2008, 2010).

O desempenho eleitoral de Lula na eleição presidencial de 2006 foi bastante similar ao observado na eleição de 2002 a despeito dos ganhos eleitorais entre os pobres, o que implica que ele perdeu pelo menos a mesma quantidade relativa de votos que ganhou. A tese comumente propagada pela mídia e pela academia é de que voto do rico é determinado por motivações distintas das dos pobres. Hunter e Power (2007, p. 14) afirmam que, enquanto os eleitores pobres respondem primariamente a melhorias em suas condições materiais de vida, os ricos dão peso maior a valores pós-materiais, como a ética e a transparência na política, e teriam reagido primariamente ao escândalo do mensalão. Essa tese também é aventada por Singer (2009, p. 84), ao afirmar que Lula perdeu boa parte de seu eleitorado de classe média durante o período do mensalão. Rennó (2007, p. 277) analisou dados do Estudo Eleitoral Brasileiro (Eseb) de 2002 e 2006 e demonstrou que eleitores com maior percepção da corrupção tenderam a votar mais em Lula no segundo turno da eleição presidencial de 2006. No entanto, esse resultado foi revisto pelo próprio autor em estudos posteriores com coautores, os quais demonstraram que eleitores com maior percepção da corrupção votaram menos em Lula em 2006 (Licio, Rennó e Castro, 2009, p. 47) e que os "lulistas novos" (aqueles que votaram em Lula apenas em 2006) são menos propensos a ver a corrupção como problema nacional do que os "lulistas antigos" (Rennó e Cabello, 2010, p. 51).

É mais plausível, no entanto, que motivações materiais e denúncias de corrupção determinem o comportamento eleitoral de forma interativa. Em vista da forte cobertura midiática dos escândalos do mensalão nos meses que precederam o pleito de 2006, é improvável que os pobres estivessem alheios aos acontecimentos. Assim, suas percepções sobre a corrupção deveriam ter afetado seu voto, não fossem os benefícios do Bolsa Família. O raciocínio sobre o comportamento eleitoral dos ricos deve ser construído de forma semelhante: teriam os ricos punido o candidato Lula pelo escândalo do mensalão se sua renda disponível tivesse crescido a taxas semelhantes às observadas entre os pobres? A forte ênfase do governo na agenda social pode tê-los levado a associar o Bolsa Família e outras políticas focalizadas a custos de oportunidade. Os recursos públicos, na mente das elites, poderiam ter sido mais bem investidos em estímulos à atividade produtiva, pois isso promoveria a geração de empregos e levaria os pobres a melhorar sua renda através do próprio trabalho. Esse tipo de pensamento é retratado em estudos sobre as atitudes das elites econômicas brasileiras ante a desigualdade social do país. Existe uma "consciência social" entre elas, mas também uma surpreendente falta de disposição para agir (López, 2013; Reis e Moore, 2005). Em termos de estratégias para a área social, é bastante disseminada a rejeição a políticas que promovem a igualdade de renda, como o Bolsa Família, em favor de políticas que estimulam a igualdade de oportunidades, como aquelas voltadas a educação, saúde e moradia (Reis, 2005). 
Assim, a forte premissa que motiva este artigo é de que o programa Bolsa Família e demais políticas redistributivas geraram reações opostas nas diferentes classes sociais brasileiras. Para demonstrar isso, eu primeiro discuto a queda das desigualdades sociais e regionais observadas durante o primeiro mandato do governo Lula e analiso diferenças nas atitudes de pobres e ricos ante essa tendência através de dados do Americas Barometer (Latin American Public Opinion Project - Lapop) 2007. Em seguida, proponho um modelo teórico destinado a prever o impacto de um programa de TRC na flutuação eleitoral do candidato governista no nível das unidades subnacionais. O modelo prevê que a direção e a magnitude dessa flutuação dependem da estrutura de classes de cada uma das unidades. Então, eu analiso um banco de dados municipais para testar as predições do modelo e demonstro que, realmente, o desempenho eleitoral de Lula entre 2002 e 2006 melhora à medida que a cobertura do Bolsa Família cresce e piora à medida que o tamanho da classe alta cresce. Ambos os efeitos são comparáveis em termos de intensidade e explicam em conjunto o rearranjo das bases eleitorais de Lula, mesmo levando-se em conta a autocorrelação espacial do termo estocástico. Por fim, discuto as implicações substantivas desses resultados.

\section{Queda da desigualdade e atitudes de pobres e ricos}

No dia primeiro de janeiro de 2003, Fernando Henrique Cardoso passou a faixa presidencial para o presidente recém-eleito Lula. Após três derrotas eleitorais consecutivas, o candidato do PT havia finalmente vencido, prometendo lutar contra a pobreza, criar empregos e formar um novo pacto social entre patrões, trabalhadores e governo. Lula melhorou seu desempenho eleitoral em quase todos os estados do país entre 1998 e 2002 e o mapa eleitoral de 2002 não indicava fortes contrastes regionais em sua votação. Em ambas as eleições, o candidato foi pouco melhor nos estados do Sul e Sudeste, mas a variação geográfica de seu apoio eleitoral não está substantivamente associada ao nível municipal de desenvolvimento. No primeiro turno da eleição de 2002, a correlação entre renda per capita e proporção municipal de votos em Lula foi de 0,26, numa amostra de 5.504 municípios.

Já no início de seu mandato, Lula anunciou e implementou sua estratégia de luta contra a pobreza. Todos os programas federais que destinavam algum tipo de auxílio financeiro a famílias pobres foram unificados num grande programa de TRC: o Bolsa Família. Famílias com renda per capita inferior a R\$100,00 se tornaram elegíveis para o recebimento de uma bolsa mensal, com a condição de manterem as crianças na escola e levá-las regularmente ao médico. Analistas têm debatido sobre a contribuição do programa para a queda do nível de desigualdade no país. Muitos deles creem que o impacto foi positivo e importante (Hoffmann, 2006; Soares et al., 2006; Haddad, 2008). Alguns ainda salientam que essa não foi a única ação do governo que contribuiu significativamente para a redução do índice de Gini (Barros, Foguel e Ulyssea, 2006). Para nossos propósitos não importa muito saber o efeito exato de cada programa do 
governo. É suficiente notar que todos fizeram parte da agenda social do governo e que tiveram seus efeitos sobre a redução da pobreza somados em maior ou menor medida ao do Bolsa Família.

Figura 1

Evolução do índice de Gini no Brasil

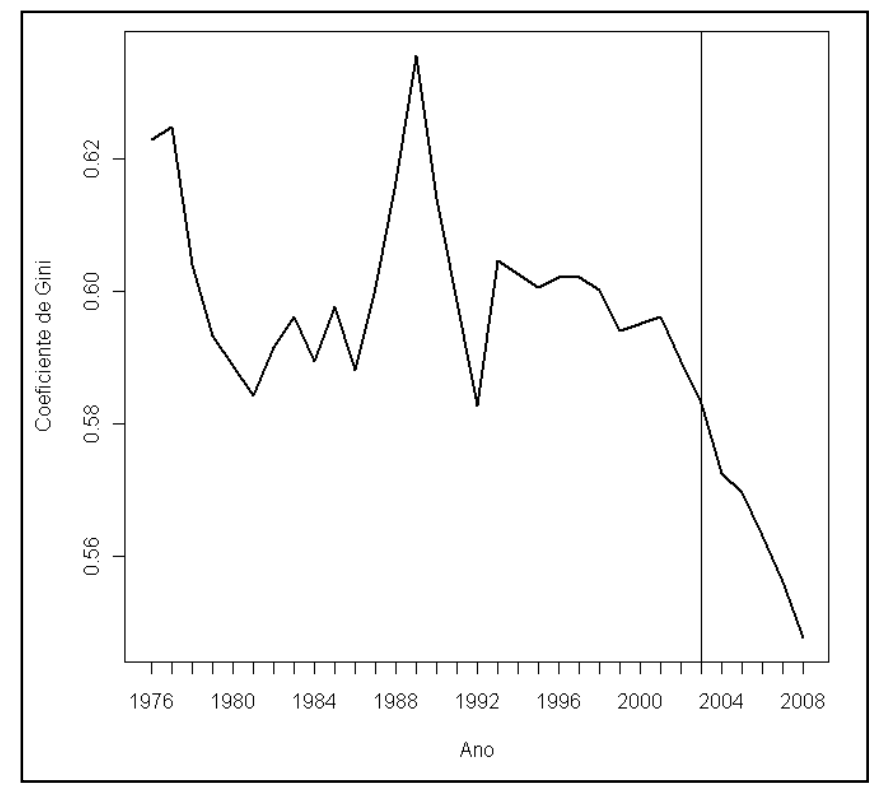

Fonte: Ipeadata.

Nota: A linha vertical indica o ano em que Lula foi eleito presidente pela primeira vez.

A Figura 1 sugere que as políticas sociais implementadas pelo presidente Lula em seu primeiro mandato foram eficazes. A queda de 0.027 ponto no coeficiente de Gini em um período de quatro anos (de 0.587 em 2002 para 0.56 em 2006) é muito alta se comparada à tendência dos anos anteriores. Além disso, esses investimentos foram proporcionalmente maiores nos municípios com maior número de famílias pobres, os quais estão concentrados na região Nordeste. Em média, a renda per capita da região mais pobre (Nordeste) cresceu a uma taxa anual superior em dois pontos percentuais à taxa da região mais rica (Sudeste) ao longo dos quatro anos. A Figura 2 mostra que a razão entre a renda per capita do Nordeste e a do Sudeste cresceu de 0,443 em 2002 para 0,478 em 2006. Apesar de o país permanecer geograficamente bastante desigual, as discrepâncias econômicas regionais foram reduzidas significativamente durante o primeiro mandato de Lula. 
Figura 2

Variação da razão entre a renda per capita do Nordeste e do Sudeste

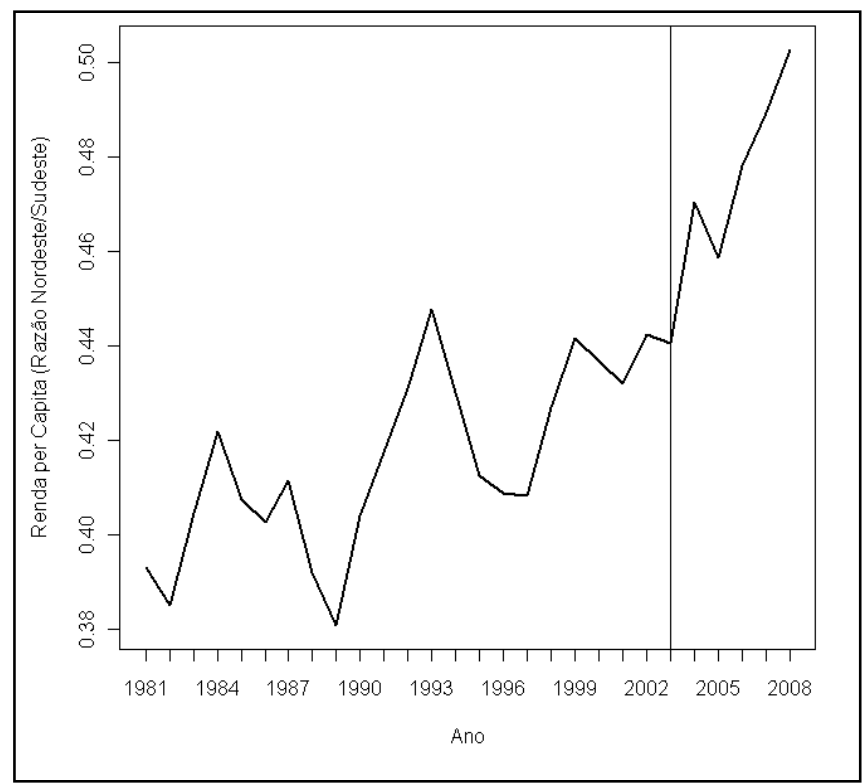

Fonte: Ipeadata e cálculos do autor.

Nota: A linha vertical indica o ano em que Lula foi eleito presidente pela primeira vez. Os valores da renda per capita estão em R\$ de 2008.

Uma das principais consequências da queda da desigualdade social e regional no Brasil foi o aumento das diferenças nas atitudes de eleitores pertencentes a classes sociais distintas. Algumas dessas diferenças são retratadas no survey do Americas Barometer (Lapop) realizado no Brasil em 2007 com uma amostra de 1.214 entrevistados. Esses dados nos permitem ter uma dimensão da distância entre as atitudes de pobres e ricos apenas alguns meses após a eleição presidencial de 2006. Algumas questões pediam que os entrevistados indicassem suas opiniões e atitudes em escalas numéricas e a Tabela 1 compara a média das respostas dadas por membros da classe pobre e da classe alta ${ }^{6}$. Esse tipo de comparação é uma abordagem analítica comum em estudos que buscam retratar o grau de polarização entre grupos distintos (DiMaggio, Evans e Bryson, 1996; Hetherington, 2009).

\footnotetext{
${ }^{6}$ Para tornar a exposição desses dados coerente com o modelo teórico e a análise empírica apresentados nas seções seguintes, utilizo um critério puramente técnico para definir o pertencimento do entrevistado à classe pobre e à classe alta. À primeira pertencem os beneficiários de programas de transferência de renda (Bolsa Família, Bolsa Escola, Bolsa Alimentação e Auxílio Gás) e à segunda, aqueles que possuíam renda familiar superior a $\mathrm{R} \$ 2.600,00$, a primeira categoria de renda fixada pelo Americas Barometer acima da renda familiar média no Brasil de acordo com a Pesquisa de Orçamentos Familiares (POF) realizada em 2002 (R\$1.899,79).
} 
Tabela 1

Atitudes de pobres e ricos com relação ao governo

\begin{tabular}{|c|c|c|c|}
\hline Indicadores do survey & Pobres & Ricos & Pobres - Ricos \\
\hline \multicolumn{4}{|l|}{$\begin{array}{l}\text { Avaliação do atual governo federal: } \\
1 \text { (Nada) - } 7 \text { (Muito) }\end{array}$} \\
\hline $\begin{array}{l}\text { Até que ponto você diria que o atual } \\
\text { governo federal combate a pobreza? }\end{array}$ & 4,38 & 3,35 & $1,03 * * *$ \\
\hline $\begin{array}{l}\text { Até que ponto você diria que o atual } \\
\text { governo federal combate a corrupção? }\end{array}$ & 3,62 & 2,92 & $0,70 * * *$ \\
\hline $\begin{array}{l}\text { Até que ponto você diria que o atual } \\
\text { governo federal combate o desemprego? }\end{array}$ & 3,54 & 3,16 & 0,38 \\
\hline \multicolumn{4}{|l|}{ Avaliações de Lula e Alckmin (1 - 10) } \\
\hline $\begin{array}{l}\text { Quanto o Lula defende os interesses dos } \\
\text { pobres? }\end{array}$ & 7,21 & 5,67 & $1,54 * * *$ \\
\hline $\begin{array}{l}\text { Em relação à honestidade, que nota o } \\
\text { senhor daria ao Lula? }\end{array}$ & 6,97 & 5,59 & $1,38 * * *$ \\
\hline $\begin{array}{l}\text { Em relação à competência administrativa, } \\
\text { que nota o senhor daria ao Lula? }\end{array}$ & 6,98 & 5,70 & $1,28 * * *$ \\
\hline $\begin{array}{l}\text { Quanto o Alckmin defende os interesses } \\
\text { dos pobres? }\end{array}$ & 5,25 & 4,84 & 0,41 \\
\hline $\begin{array}{l}\text { Em relação à honestidade, que nota o } \\
\text { senhor daria ao Alckmin? }\end{array}$ & 4,88 & 5,11 & $-0,23$ \\
\hline $\begin{array}{l}\text { Em relação à competência administrativa, } \\
\text { que nota o senhor daria ao Alckmin? }\end{array}$ & 5,45 & 5,69 & $-0,24$ \\
\hline \multicolumn{4}{|l|}{$\begin{array}{l}\text { Opiniões gerais sobre as } \\
\text { desigualdades no Brasil: } 1 \text { (Discorda } \\
\text { Totalmente) - } 5 \text { (Concorda } \\
\text { Totalmente)* }\end{array}$} \\
\hline $\begin{array}{l}\text { O Brasil estaria bem melhor se nos } \\
\text { preocupássemos menos com que todo } \\
\text { mundo seja igual. }\end{array}$ & 2,92 & 2,62 & 0,30 \\
\hline $\begin{array}{l}\text { Nós teríamos menos problemas no Brasil } \\
\text { se as pessoas fossem tratadas com mais } \\
\text { igualdade. }\end{array}$ & 4,41 & 4,37 & 0,04 \\
\hline $\begin{array}{l}\text { Em um país como o Brasil, é obrigação do } \\
\text { governo diminuir as diferenças entre os } \\
\text { muito ricos e muito pobres. }\end{array}$ & 4,13 & 4,10 & 0,03 \\
\hline $\begin{array}{l}\text { Se o país for rico, não importa que haja } \\
\text { muitas desigualdades econômicas e } \\
\text { sociais. }\end{array}$ & 2,34 & 2,00 & $0,34 * *$ \\
\hline $\mathbf{N}$ & 159 & 94 & \\
\hline
\end{tabular}

Fonte: Elaboração própria, com base em dados do Americas Barometer 2007.

* Originalmente essa variável tinha escala 1-4. Eu a recodifiquei, dando valor 3 à categoria

"nem concorda, nem discorda", em vez do valor original 6. As categorias "concorda" e

"concorda totalmente" foram recodificadas como 4 e 5 , respectivamente.

Nota: Nível de significância em testes t para diferença de médias: ** $\mathrm{p}<0,05 ; * * * \mathrm{p}<0,01$.

Em primeiro lugar, note que quando questionados sobre a atuação do governo federal no combate à pobreza, corrupção e desemprego, o maior grau de divergência se deu com relação ao primeiro item. Em geral, indivíduos pobres deram melhores avaliações que os ricos em todos os itens, mas os ricos estavam especialmente menos convencidos que os pobres quanto ao compromisso do governo com o combate à pobreza. Apenas a diferença de suas opiniões com relação à atuação do governo no 
combate ao desemprego não é estatisticamente significante. Um padrão similar pode ser observado no modo como ambos os grupos avaliaram os dois principais candidatos na eleição de 2006. Os pobres deram notas sistematicamente maiores para Lula em todos os itens, mas a diferença é maior quando perguntados se o presidente defendia os interesses dos pobres. Por outro lado, não houve muito desacordo entre ricos e pobres com relação às avaliações do candidato oposicionista Geraldo Alckmin.

Os ricos pareciam estar tão convencidos quanto os pobres da necessidade de combater a pobreza e reduzir as desigualdades sociais. Note na parte inferior da Tabela 1 o quão próximas são as opiniões de ambas as classes sobre as desigualdades sociais no Brasil. O único item em que a diferença de opiniões é estatisticamente significante se refere à afirmação de que num país rico as desigualdades econômicas e sociais não seriam importantes. Contraintuitivamente, os ricos discordaram mais dessa afirmação do que os pobres. Assim, a fonte de divergência entre as classes sociais parece se centrar nas ações efetivas tomadas pelo governo, não no objetivo de redução da pobreza e da desigualdade. Como sugerido pelas declarações da mulher do candidato Serra e do senador Jereissati, pela cobertura negativa recebida pelo Bolsa Família na imprensa brasileira e pelos estudos citados acima sobre o modo como pensam as elites econômicas do país, políticas de renda mínima são encaradas por essas elites como estímulos à vagabundagem, como prejudiciais à oferta de mão de obra e ao desenvolvimento do país. Divergências com relação à melhor estratégia no combate à pobreza provavelmente explicam o ceticismo das classes altas com relação à administração de Lula e seu real comprometimento com os pobres. Para entender melhor as implicações políticas dessas atitudes, proponho na seção seguinte um modelo teórico que prediz o impacto de um grande programa de TRC como o Bolsa Família sobre o desempenho eleitoral do candidato presidencial governista no nível das unidades subnacionais.

\section{Estrutura de classes, redistribuição de renda e eleições}

Considere que cada país seja composto por três classes sociais - os pobres, a classe média e os ricos - e que os seus tamanhos relativos sejam, respectivamente $p, m$ e r. A soma dessas três proporções é um. Cidadãos pobres são elegíveis para receber benefícios do programa de TRC; cidadãos ricos ganham acima da média nacional; e os demais cidadãos, aqueles que ganham abaixo da média nacional mas não são elegíveis para o programa de TRC, pertencem à classe média. $O$ tamanho de cada classe $(p, m$ e $r$ ) e o valor da renda que as separa variam de país a país e dependem de três fatores. Primeiro, o critério de elegibilidade do programa de TRC determina o tamanho dos pobres e da classe média, assim como o valor da renda que os separa. Dessa forma, a definição de pobreza é uma decisão política feita por cada governo nacional. Segundo, o tamanho da classe média e dos ricos, assim como o valor da renda que os separa, depende do nível de desigualdade. Quanto mais desigual for o país, menor é a porcentagem da população que ganha acima da média nacional. Consequentemente, em 
países altamente desiguais com um programa de TRC restritivo, a classe média é enorme. Por outro lado, em países igualitários com um programa de TRC generoso, a classe média é pequena. Finalmente, o valor da renda que separa uma classe da outra também depende do nível de desenvolvimento de cada país. Em países desenvolvidos, os dois valores que definem a estrutura de classes nacional serão provavelmente maiores do que em países em desenvolvimento.

Classes são definidas no nível nacional, porque seus tamanhos relativos dependem dos critérios de elegibilidade de um programa nacional de TRC, do nível nacional de desigualdade e do nível nacional de desenvolvimento. No entanto, a estrutura de classes das unidades subnacionais (estados, províncias, municípios, distritos etc.) pode variar. Pode haver unidades em que a maioria da população ganha acima da média nacional e unidades em que a maioria é pobre e elegível para participar de programas de TRC. No município $i$, o tamanho relativo dos pobres, da classe média e dos ricos é, respectivamente, $p_{i}, m_{i}$ e $r_{i}$, e a soma dessas proporções é sempre um.

Considere também três pontos no tempo: $t_{-1}, t$ e $t_{+1}$. Em $t_{-1}$, o candidato $I$ é eleito presidente pela primeira vez; em $t$, ele implementa um programa de TRC; e, em $t_{+1}$, ele concorre à reeleição. Em ambas as eleições, $I$ concorre contra o mesmo oponente $O$, que faz as mesmas promessas e tem a mesma ideologia. Os eleitores usam dois critérios para escolher entre os candidatos: 1) a percepção do impacto das políticas do governo anterior nas suas condições de vida (voto retrospectivo) e 2) tudo o mais (ideologia, identidade partidária etc.). Como $t_{-1}$ é o primeiro ponto no tempo, o único critério utilizado pelos indivíduos para escolher entre $I$ e $O$ nesse período é "tudo o mais". A probabilidade de um cidadão votar em $I$ em $t_{-1}$ é função desse critério e é expressa pelo termo I, um parâmetro que varia de $0 \%$ a $100 \%$. Analogamente, a probabilidade de o mesmo cidadão votar em $O$ é $(1-l)$. O parâmetro $/$ é também a probabilidade de um cidadão escolhido aleatoriamente votar em $I$ em $t_{-1}$ e, portanto, corresponde à proporção nacional de votos de $I$ naquela eleição.

Por diversas razões, o valor desse parâmetro pode variar entre diferentes segmentos da população. A probabilidade do voto em $I$ pode variar entre grupos de idade, níveis educacionais, filiação partidária etc. Considere que o valor desse parâmetro varia apenas entre classes sociais e que a probabilidade de um cidadão pobre, um cidadão de classe média e um cidadão rico votar em $I$ em $t_{-1}$ seja, respectivamente, $I_{P}, I_{M}$ e $I_{R}$. Consequentemente, a proporção nacional de votos de $I$ naquela eleição será $p I_{P}+$ $m l_{M}+r l_{R}$, enquanto a proporção de votos de $O$ será $1-\left(p l_{P}+m I_{M}+r l_{R}\right)$. Dado que $I$ vence, sua proporção de votos é necessariamente maior que a de $O$.

Como foi dito anteriormente, o tamanho de cada classe varia nas diferentes unidades subnacionais. Portanto, a proporção de votos de $I$ na unidade $i$ em $t_{-1}$ é:

$$
V_{i, t-1}^{I}=p_{i} l_{P}+m_{i} l_{M}+r_{i} l_{R}
$$


Em $t$, um programa de TRC é implementado pelo presidente $I$. Uma vez adotado, o programa aumenta automaticamente a renda disponível dos pobres. As demais classes sociais pagam custos de oportunidade pela utilização de recursos públicos em políticas que não Ihes beneficiam diretamente. Assim, a não ser que membros dessas classes identifiquem algum benefício indireto do programa que supere os custos de oportunidade, suas atitudes com relação a programas de TRC serão necessariamente negativas. Benefícios indiretos ocorrem, por exemplo, quando o maior poder de compra dos pobres afeta positivamente a economia local. Porém, em países regionalmente desiguais como o Brasil, onde a maioria dos ricos vive em municípios com poucos pobres e a maioria dos pobres vive em municípios com poucos ricos, é provável que os efeitos indiretos do programa na economia local sejam imperceptíveis para aqueles que ganham acima da média nacional. Nesses casos, a expectativa é de que a classe alta identifique primariamente custos de oportunidade na implementação de programas de TRC. A classe média é social e geograficamente mais próxima da classe pobre e seus membros são mais suscetíveis a identificar efeitos positivos indiretos do programa, seja por se beneficiarem mais intensamente de estímulos na economia local, seja por terem parentes ou amigos beneficiários, ou ainda por se verem em risco de ter que recorrer ao programa no futuro. A percepção desses efeitos indiretos poderia reduzir ou neutralizar a potencial oposição dessa classe à existência do programa. Para simplificar as análises que se seguem, assumo que as atitudes da classe média são neutras; isto é, para seus membros os benefícios indiretos do programa equivalem aos custos de oportunidade e, portanto, a implementação de um programa de TRC não afeta seu comportamento eleitoral.

Apoio e oposição a políticas implementadas por I se refletem na arena eleitoral. O governo investe em muitas políticas diferentes ao longo do seu mandato e a implementação de um programa de transferência de renda não determina totalmente em quem cada cidadão vota. Mas ela determina o comportamento eleitoral dos cidadãos de forma probabilística: programas de TRC aumentam (diminuem) a probabilidade de seus apoiadores (opositores) votarem em $I$. Assim, dado que um programa de TRC foi implementado em $t$, a probabilidade de um membro da classe pobre e rica votar em $I$ em $t_{+1}$ é:
a) pobre: $l_{P}(1+\alpha)$
b) rico: $l_{R}(1-\beta)$

onde $\alpha$ é o parâmetro que capta o efeito positivo do programa sobre a probabilidade de um cidadão pobre votar em $I$ e $\beta$ capta o efeito negativo do programa sobre a probabilidade de um cidadão rico votar em $I$. Os parâmetros $\alpha$ e $\beta$ podem também ser interpretados como efeitos diretos do programa sobre o apoio eleitoral de $I$; o primeiro captando a percepção dos pobres quanto ao impacto positivo do programa em suas condições de vida e o segundo captando a percepção dos ricos em relação aos custos de 
oportunidade que estão pagando pela canalização de recursos públicos em uma política que não thes beneficia. Esses mesmos parâmetros com sinais invertidos explicam a influência do programa de TRC sobre o apoio eleitoral de $O$.

Os valores de $\alpha$ e $\beta$ podem ser também influenciados por fatores contextuais. Por exemplo, o valor de $\beta$ pode ser menor quando $I$ é filiado a um partido de direita, porque os ricos geralmente preferem presidentes conservadores. Outros exemplos de fatores que podem influenciar o valor desses parâmetros são o tamanho e a visibilidade do programa de TRC, outras ações do governo, a disponibilidade de informações e o apoio eleitoral que o presidente recebeu de cada classe na eleição anterior (i.e., $I_{P}, I_{M}$ e $I_{R}$ ). A análise do efeito desses fatores contextuais não está entre os meus objetivos neste artigo, mas, intuitivamente, parece razoável assumir que eles não são capazes de mudar o sinal de $\alpha$ e $\beta$; isto é, fatores contextuais podem influenciar apenas as suas magnitudes. A implicação é de que um programa de TRC sempre afeta as atitudes de pobres e ricos em relação a $I$ e $O$ em direções opostas, tendo assim um potencial muito forte para polarizar politicamente o país em termos de classe.

Como resultado dessa polarização, a proporção de votos de $I$ na unidade $i$ em $t_{+1}$ é:

$$
V_{i, t+1}^{I}=p_{i}\left(l_{P}+\alpha l_{P}\right)+r_{i}\left(l_{R}-\beta l_{R}\right)+m_{i} l_{M}
$$

Isto é, uma vez que um programa de TRC é iniciado, o apoio eleitoral de $I$ aumenta entre os pobres a uma taxa $\alpha$, diminui entre os ricos a uma taxa $\beta$ e não muda entre a classe média. A equação (2) também mostra que, apesar de o programa de TRC sempre polarizar o eleitorado em termos de classe, essa polarização não necessariamente afeta a proporção de votos de $I$ na unidade subnacional $i$. Se $I$ perde tantos votos entre os ricos quanto ganha entre os pobres, as proporções de voto de $I$ e de $O$ não mudam naquela localidade de uma eleição a outra. Como consequência, a comparação entre o desempenho eleitoral de $I$ em $t_{-1}$ e em $t_{+1}$ na mesma unidade subnacional não nos permite obter uma estimativa precisa da polarização eleitoral gerada por programas de TRC, pois a manutenção de um mesmo desempenho não significa que não houve polarização em seu eleitorado.

Por outro lado, como os efeitos do programa dependem da estrutura de classes da unidade, a sua influência sobre o desempenho eleitoral de $I$ necessariamente varia de unidade para unidade quando suas respectivas estruturas de classes mudam. A expectativa é de que o presidente perca votos em lugares onde os ricos são suficientemente mais numerosos que os pobres, ganhe votos onde os pobres são suficientemente mais numerosos que os ricos e mantenha a mesma performance onde o tamanho das classes está em equilíbrio. Esse equilíbrio não é necessariamente obtido quando as duas classes possuem o mesmo tamanho, porque ele também depende dos outros parâmetros da equação (2). 
A flutuação da votação de $I$ no município $i$ de uma eleição para a outra é expressa pela diferença entre (2) e (1):

$$
\Delta V_{i}^{I}=p_{i}\left(l_{P}+\alpha l_{P}\right)+r_{i}\left(l_{R}-\beta l_{R}\right)+m_{i} l_{M}-p_{i} l_{P}-m_{i} l_{M}-r_{i} l_{R}
$$

cuja forma reduzida é:

$$
\Delta V_{i}^{I}=p_{i}\left(\alpha l_{P}\right)-r_{i}\left(\beta l_{R}\right)
$$

A equação (4) mostra que a flutuação da votação de $I$ em cada unidade gerada pela implementação de um programa de TRC é uma função da estrutura de classes da unidade. O primeiro termo no lado direito da equação $\left(p_{i}\left(\alpha l_{P}\right)\right)$ é chamado efeito pobreza do programa de TRC, porque ele reflete a influência positiva do programa sobre os votos dos pobres. O segundo termo no lado direito da equação $\left(r_{i}\left(\beta l_{R}\right)\right)$ é chamado efeito riqueza, porque ele reflete o efeito negativo do programa sobre os votos dos ricos. A equação mostra que a flutuação da votação em $I$ na unidade $i$ é positiva quando o efeito pobreza é maior que o efeito riqueza, negativa quando ocorre o oposto e igual a zero quando ambos os efeitos se equivalem.

\section{Estrutura de classes e o desempenho eleitoral de Lula em 2006}

No modelo proposto na seção anterior, o sinal e a magnitude da flutuação da votação de $I$ em cada unidade subnacional dependem primariamente de três pares de fatores: a probabilidade de pobres e ricos terem votado em $I$ em $t_{-1}\left(I_{P}\right.$ e $\left.I_{R}\right)$, o efeito da implementação de um programa de TRC sobre aquelas probabilidades $(\alpha$ e $\beta$ ) e o tamanho das classes baixa e alta em cada unidade $\left(p_{i}\right.$ e $\left.r_{i}\right)$. Os dois primeiros pares de fatores são constantes no nível de análise das unidades subnacionais de um mesmo país. Eles captam características contextuais e devem variar apenas entre países e administrações presidenciais. O terceiro par é variável entre as unidades subnacionais, sendo também o foco deste artigo nas análises apresentadas a seguir. A expectativa é de que, quando um governo implementa um programa de TRC, a flutuação de seu apoio eleitoral nas eleições seguintes seja negativamente associada à proporção de ricos e positivamente associada à proporção de pobres.

O modelo proposto nos ajuda a entender o que ocorreu no Brasil durante as eleições de 2006 e o papel que a implementação do programa Bolsa Família teve no desempenho eleitoral de Lula, o candidato à reeleição. Para demonstrar isso, analisei dados do Tribunal Superior Eleitoral (TSE), do censo de 2000 e do Ministério de Desenvolvimento Social e de Combate à Fome (MDS) e estimei modelos de regressão linear usando a flutuação da votação de Lula entre as eleições de 2002 e 2006 como 
variável dependente ${ }^{7}$. Essa variável pode assumir valores entre -1 e 1 , sendo que valores positivos indicam que Lula melhorou sua performance de uma eleição a outra, enquanto o oposto é verdadeiro para valores negativos. Analisei dados do primeiro e do segundo turnos e ambos levam exatamente às mesmas conclusões. Abaixo, apresento apenas os resultados das análises com dados do segundo turno, pois são mais coerentes com o modelo teórico de dois candidatos proposto na seção anterior.

As principais variáveis independentes são a proporção de ricos e a proporção de pobres em cada município. Como dito acima, estes são os únicos parâmetros do modelo teórico que variam entre os municípios, e portanto os únicos capazes de afetar a variação do desempenho eleitoral de Lula nesse nível de análise. A proporção de pobres foi calculada dividindo-se o número de famílias que recebem benefícios do Bolsa Família em 2006 pelo número total de famílias do município de acordo com o censo de 2000. Com relação à proporção de ricos, o IBGE possui dados sobre a porcentagem da população ganhando mais de cinco salários mínimos ( $R \$ 755,00)$ e mais de dez salários mínimos ( $R \$ 1.510,00)$ em 2000, ano em que a renda média dos brasileiros foi de $R \$ 1.117,95$. Estimei modelos usando os dois valores e todos levam a conclusões semelhantes. Abaixo mostro apenas os resultados com o indicador menos conservador para a proporção de ricos: a quantidade relativa da população ganhando mais de cinco salários mínimos. Incluí também uma interação entre essas duas variáveis independentes para testar uma implicação do modelo teórico: o fato de que os efeitos pobreza e riqueza se cancelam e que, portanto, o aumento da cobertura do Bolsa Família gera menos votos para Lula à medida que a quantidade de ricos cresce. O sinal esperado para essa interação é negativo.

Como variáveis de controle, incluí algumas características municipais potencialmente importantes em pleitos eleitorais. O log da população indica sua importância enquanto mercado eleitoral e o grau de atratividade do município como foco de campanhas. A proporção de negros (pessoas classificadas pelo censo como sendo pretas ou pardas) indica a composição racial dos municípios. Finalmente, o controle da prefeitura e do governo do estado pelo PT indica o grau de influência do partido do candidato governista em cada município. Contraintuitivamente, estudos sobre as eleições de 2006 têm encontrado um efeito negativo dessas últimas variáveis (Zucco, 2008). Não incluí indicadores de desenvolvimento econômico dos municípios, pois estão altamente correlacionados com a estrutura de classes e poderiam gerar um problema de multicolinearidade nos modelos estimados.

Alguns autores chamaram a atenção para o fato de que a votação municipal de Lula em 2006 é caracterizada por uma forte dependência espacial, ou seja, sua votação num município seria também afetada pela sua votação nos municípios vizinhos (Shikida et al., 2009; Soares e Terron, 2008). Uma explicação possível para essa dependência

\footnotetext{
7 Mais especificamente, a variável dependente é simplesmente a proporção de votos válidos de Lula na eleição de 2006 menos a sua proporção de votos válidos na eleição de 2002.
} 
espacial são os efeitos de vizinhança, ocasionados, por exemplo, por fluxos de comunicação entre habitantes de cidades próximas ou por estímulos de campanhas municipais sobre eleitores registrados em outros municípios. Outra explicação possível é a influência de variáveis omitidas com efeitos geograficamente limitados, como, por exemplo, variações nos mercados midiáticos, nas estações de rádio e TV e nos esforços regionais de campanha. A maneira usual de testar a existência de autocorrelação espacial da variável dependente é através do índice I de Moran, um indicador que varia de -1 a 1 . Quanto mais próximo o seu valor estiver dos extremos da escala, maior é a autocorrelação espacial da variável, indicando que seu valor em uma localidade é influenciado pelo seu valor em localidades vizinhas. Calculei o índice I de Moran para a flutuação da votação de Lula entre 2002 e 2006, com base em uma matriz de ponderação espacial cujo critério foi a contiguidade de primeira ordem. O valor do índice é 0,82 para o primeiro turno e 0,79 para o segundo, valores bastante altos ${ }^{8}$.

Também calculei para todos os municípios o índice I de Moran local (Lisa), que indica para cada um deles o quanto a votação de Lula foi afetada pela sua votação nos municípios limítrofes. No mapa da Figura 3, as áreas vermelhas indicam municípios com alta flutuação positiva de votos no segundo turno cercados por municípios também com alta flutuação positiva, isto é, municípios HH (abreviação em inglês para alto-alto). As áreas azuis indicam municípios com alta flutuação negativa de votos cercados por municípios com alta flutuação negativa, isto é, municípios LL (abreviação em inglês para baixo-baixo). As demais áreas coloridas são municípios $\mathrm{HL}$ ou $\mathrm{LH}$ e as áreas brancas apresentam índices Lisa insignificantes. Do total de 5.504 municípios do banco de dados, os 1.285 municípios HH se concentram no Norte e Nordeste e os 1.509 LL se concentram no Sul, Sudeste e Centro-Oeste, o que já sugere um padrão geográfico para a flutuação da votação de Lula entre 2002 e 2006. Há ainda 57 municípios LH, 22 municípios HL e 2.628 municípios com Lisa estatisticamente insignificantes. O distrito federal, por não possuir municípios, e a Ilhabela (SP) e Fernando de Noronha (PE), por serem ilhas, foram classificados como sem vizinhança.

\footnotetext{
${ }^{8}$ Para realizar a análise espacial, utilizei um mapa disponibilizado pelo IBGE com a malha municipal de 2005, ano em que o Brasil possuía 5.564 municípios. Excluí do arquivo .shp, 60 unidades (1\% do total) para as quais faltavam informações em pelo menos uma variável utilizada na análise. A maior parte delas se refere a municípios criados entre 2000 e 2005. Toda a análise empírica apresentada nesta seção foi realizada através do aplicativo livre GeoDa.
} 


\section{Figura 3 \\ Índices Lisa para a flutuação eleitoral de Lula entre 2002 e 2006 (segundo turno)}

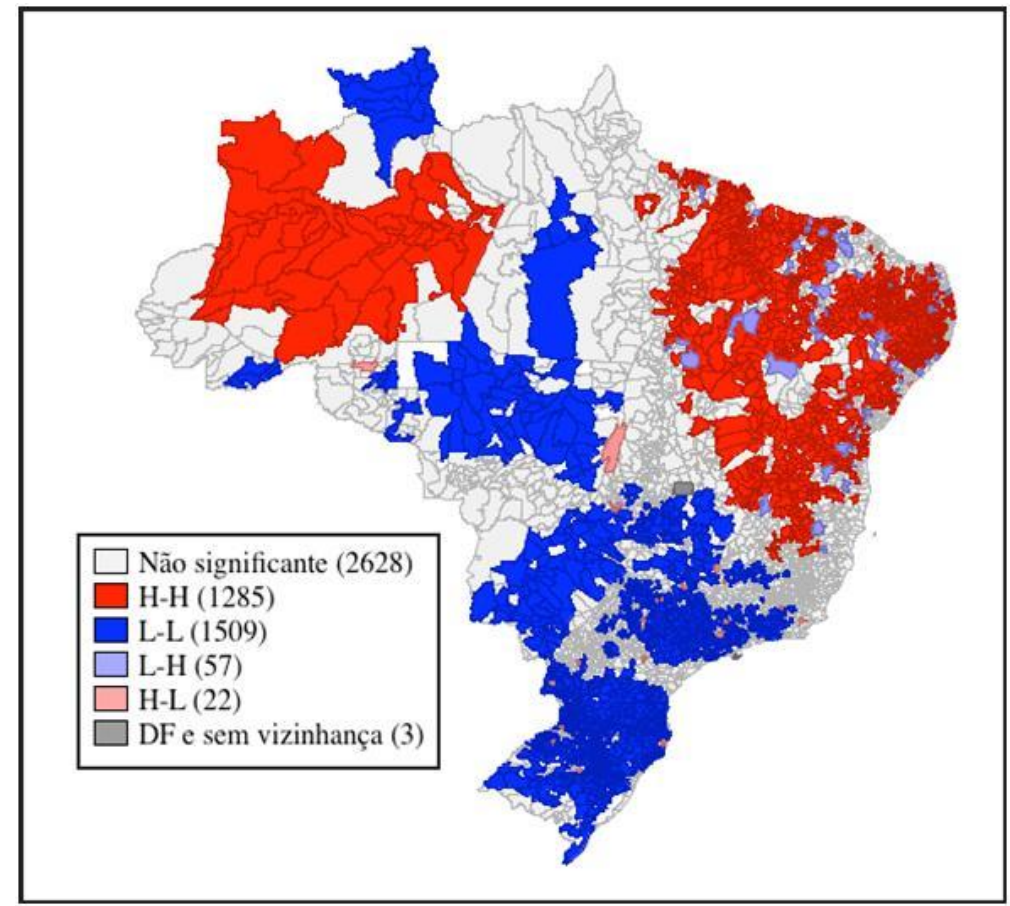

Fonte: Elaboração própria com base em dados do TSE.

Para decidir entre estimar um modelo com controle para efeitos de vizinhança (modelo de lag espacial) ou um modelo que considera a influência de variáveis omitidas (modelo de erro espacial), segui o padrão da literatura e calculei o multiplicador de Lagrange (ML) robusto para cada uma das duas opções. Ambos são significantes, mas o ML robusto para o modelo de erro espacial (435.7769) é maior do que o ML robusto para o de lag espacial (285.0721), sugerindo que o primeiro deles é o mais adequado. Esse resultado é consistente com os demais estudos que analisaram as eleições brasileiras de 2006 com instrumentos de econometria espacial (Shikida et al., 2009; Soares e Terron, 2008) e indica que a autocorrelação espacial da flutuação da votação de Lula entre 2002 e 2006 é consequência da influência de variáveis omitidas com efeitos geograficamente limitados. Estimei modelos com controle para a autocorrelação espacial do termo estocástico (lambda) e modelos sem controle. Os resultados podem ser observados na Tabela 2: 
Tabela 2

Modelos OLS: flutuação da votação do Lula no $2^{\circ}$ turno

\begin{tabular}{|l|c|c|c|c|}
\hline Variável & Modelo 1 & Modelo 2 & Modelo 3 & Modelo 4 \\
\hline $\begin{array}{l}\text { Cobertura do Bolsa Família } \\
\text { em 2006 }\end{array}$ & $0,70 * * *$ & $0,40 * * *$ & $0,58 * * *$ & $0,40 * * *$ \\
\hline $\begin{array}{l}\text { Proporção de ricos em } \\
2000\end{array}$ & $-0,26 * * *$ & $-0,32 * * *$ & $-0,19 * * *$ & $-0,28 * * *$ \\
\hline $\begin{array}{l}\text { Interação (Bolsa Família } \times \\
\text { ricos) }\end{array}$ & $-1,44 * * *$ & $-1,10 * * *$ & $-2,33 * * *$ & $-1,24 * * *$ \\
\hline Log da população em 2000 & & & $0,02 * * *$ & 0,01 \\
\hline $\begin{array}{l}\text { Proporção de negros em } \\
2000\end{array}$ & & & $0,16 * * *$ & $0,15 * * *$ \\
\hline $\begin{array}{l}\text { Governador do PT (2002- } \\
\text { 2006) }\end{array}$ & & & $-0,07 * * *$ & $-0,06 * * *$ \\
\hline Prefeito do PT (2004-2008) & $-0,12 * * *$ & $-0,01$ & $-0,20 * * *$ & $-0,09 * * *$ \\
\hline Constante & & $0,77 * * *$ & & $0,72 * * *$ \\
\hline Lambda & 5.504 & 5.504 & 5.504 & 5.504 \\
\hline $\mathrm{N}$ & 0,64 & 0,80 & 0,67 & 0,80 \\
\hline $\mathrm{R}^{2}$ & & & $-0,04 * * *$ & $-0,03 * * *$ \\
\hline
\end{tabular}

Fonte: Elaboração própria, com base em dados do TSE, MDS e Censo 2000.

Nota: Nível de significância: $* * * \mathrm{p}<0.01$.

O primeiro modelo não possui variáveis de controle, o segundo controla apenas a autocorrelação espacial do erro, o terceiro possui controles apenas para as características municipais descritas acima e o quarto modelo possui todos os controles. Em primeiro lugar, note que os modelos sem as variáveis de controle já possuem um $\mathrm{R}^{2}$ consideravelmente alto, sugerindo um forte poder explicativo da estrutura de classes sobre a flutuação de votos de Lula de 2002 para 2006. Para cada 1 ponto percentual de famílias beneficiadas pelo Bolsa Família, Lula teria recebido quase 0,7 ponto percentual a mais de votos entre 2002 e 2006; e para cada 1 ponto percentual de eleitores ricos, Lula teria perdido cerca de 0,26 ponto percentual de votos. Apesar da diferença na magnitude desses efeitos, é preciso chamar a atenção para o fato de que as cidades mais populosas tendem a ter relativamente mais ricos e menos beneficiários do programa Bolsa Família. Isso implica que o efeito riqueza se processa sobre uma maior quantidade absoluta de votos comparativamente ao efeito pobreza. Note também que a interação é, como esperado, negativa e significante. Isso demonstra que ambos os efeitos realmente se neutralizam: o aumento de beneficiários do Bolsa Família gera menos votos a Lula à medida que a quantidade de ricos cresce. Todos os controles possuem efeitos significativos e com sinais idênticos aos comumente encontrados pela literatura.

$\mathrm{Na}$ minha amostra, o município de Acauã (PI) era o mais pobre, com uma população de 2.002 habitantes em 2000, uma proporção de ricos igual a zero e uma proporção de beneficiários do Bolsa Família estimada em cerca de 95\%. Nesse município, Lula recebeu 55,46\% dos votos válidos no segundo turno da eleição de 2002 e 80,71\% 
no da eleição de 2006. A flutuação de sua votação foi, portanto, positiva em 25,25 pontos percentuais. Por outro lado, o município mais rico da minha amostra era São Caetano do Sul (SP), com 140.159 habitantes em 2000, uma proporção de ricos de $52,68 \%$ e uma proporção de beneficiários do Bolsa Família de 3,15\%. Nesse município, Lula obteve $52,90 \%$ dos votos no segundo turno da eleição de 2002 e apenas 34,98\% dos votos no da eleição de 2006, o que equivale a uma flutuação negativa de 17,92 pontos percentuais. Embora a perda de votos tenha sido menor na cidade mais rica do que foi o ganho na cidade mais pobre em termos percentuais, Lula perdeu uma quantidade absoluta de votos muito maior em São Caetano do Sul, em virtude do tamanho do seu eleitorado. Isso se encaixa no padrão observado durante o ciclo eleitoral de 2002 a 2006 no Brasil: as perdas eleitorais de Lula se concentraram nos municípios mais populosos onde o tamanho da classe alta tende a ser maior, enquanto seus ganhos foram dispersos pelas centenas de municípios pobres e pouco populosos, onde a cobertura do Bolsa Família foi maior.

Em conjunto, esses resultados sustentam o modelo teórico apresentado na seção anterior e sugerem que o Bolsa Família pode ter gerado custos eleitorais tão altos quanto foram os ganhos para o presidente Lula. Isso se deu na medida em que o programa foi percebido pela classe alta como um custo de oportunidade na utilização de recursos públicos. Esses resultados são uma evidência de que grandes programas de TRC polarizam o eleitorado em vez de apenas expandir as bases eleitorais do presidente entre os pobres, como tem sido argumentado pela literatura recente. O Bolsa Família não aumentou o apoio eleitoral agregado de Lula; ele promoveu uma transformação da composição socioeconômica de suas bases, com eleitores ricos migrando para a oposição e eleitores pobres se tornando governistas.

\section{Conclusões}

Nos últimos 15 anos, programas de TRC se espalharam pela América Latina e outras partes do mundo. Organizações nacionais e internacionais publicaram inúmeros relatórios elogiando 0 impacto positivo desses programas em indicadores socioeconômicos como o nível de pobreza, a desigualdade de renda, matrículas em escolas e valores nutricionais entre os pobres. É provável que presidentes de todo o continente tenham sido influenciados por esse otimismo, o que os levou a tomar iniciativas para implementar esses programas em seus países.

Não obstante, políticas redistributivas sofrem oposição de certos segmentos da população, especialmente em países desiguais. Essa oposição se reflete na arena eleitoral e presidentes que implementam programas de TRC correm o risco de perder votos. Esses custos eleitorais têm sido misteriosamente negligenciados por todos os autores que analisaram o impacto do Bolsa Família no desempenho eleitoral de Lula em 2006. Atualmente, existe um certo consenso acadêmico de que o programa estimulou os pobres a votar em favor do governo e que o seu efeito na votação de Lula em 2006 foi 
positivo. Neste artigo, apresentei evidências teóricas e empíricas de que essa interpretação precisa ser retificada. Lula ganhou pelo menos tantos votos quanto perdeu em consequência do Bolsa Família, o que explica o fato de sua proporção nacional de votos não ter mudado muito de uma eleição para outra.

Apesar de o meu foco ter sido restrito ao que ocorreu no Brasil, acredito que o modelo teórico proposto é útil para interpretar fenômenos semelhantes em outros países. A análise do impacto de programas de TRC no desempenho eleitoral de outros presidentes que o implementaram é uma forma de testar essa teoria e fazer avançar essa agenda de pesquisa. Enquanto isso não é feito, espero que os meus achados ao menos gerem ceticismo com relação a argumentos de que programas de TRC não implicam custos eleitorais e geram uma bonança eleitoral para candidatos presidenciais governistas.

É certo que investimentos em outras políticas sociais, como o Benefício de Prestação Continuada (BPC), o aumento do salário mínimo, a expansão do crédito, entre outros, também estimularam a migração de eleitores pobres às bases de apoio do governo (Singer, 2009). É certo também que escândalos de corrupção e o descontentamento com a atuação do governo em outras áreas podem ter estimulado as classes altas a migrar para a oposição (Licio, Rennó e Castro, 2009; Pereira, Rennó e Samuels, 2011). Estimar os efeitos precisos de cada um desses fatores no comportamento eleitoral dos brasileiros e na flutuação da votação de Lula soa como um exercício de análise empírica demasiadamente complicado e, possivelmente, desnecessário. A história do ciclo eleitoral de 2002-2006 é uma história sobre reações das diferentes classes à ênfase do governo no combate à pobreza e à desigualdade. $O$ Bolsa Família não foi o único instrumento utilizado nesse intento, mas foi inegavelmente o mais visível, aquele que despertou as reações mais intensas, muitas vezes exageradas, em eleitores de todas as classes sociais. Este artigo segue a abordagem corrente da literatura de elevar o programa ao patamar de principal variável explicativa para o padrão eleitoral de 2006. Sua principal contribuição para o debate é interpretar as reações negativas das classes altas também como reações à ênfase do governo na área social em geral, e no Bolsa Família em particular. No fundo, essas são reações ao fato de que, pela primeira vez em décadas, seus interesses econômicos foram relegados a um plano inferior na agenda da administração federal.

Diego Sanches Corrêa - Departamento de Ciência Política. Faculdade de Filosofia, Letras e Ciências Humanas. Universidade de São Paulo. E-mail: <diegocorreaps@gmail.com>. 


\section{Referências bibliográficas}

Barros, R. P.; Foguel, M. N.; Ulyssea, G. (eds.). Desigualdade de renda no Brasil: uma análise da queda recente. Brasília, DF: Ipea, 2006.

Biroli, F.; MANTOVANI, D. "Disputas, ajustes e acomodações na produção da agenda eleitoral: a cobertura jornalística ao programa Bolsa Família e as eleições de 2006". Opinião Pública, vol. 16, n 1, p. 90-116, jun. 2010.

DiMAGgIO, P.; EVANS, J.; BRYSON, B. "Have American's social attitudes become more polarized?". American Journal of Sociology, vol. 102, n 3, p. 690-755, 1996.

HADDAD, M. A. "Bolsa Família and the needy: is allocation contributing to equity in Brazil?". Journal of International Development, vol. 20, n 5, p. 654-669, 2008.

Hetherington, M. J. "Review article: putting polarization in perspective". British Journal of Political Science, vol. 39, n², p. 413-448, abr. 2009.

HoffmAnN, R. "Transferências de renda e a redução da desigualdade no Brasil e cinco regiões entre 1997 e 2004". Econômica, vol. 8, n 1, p. 55-81, 2006.

HUNTER, W.; POWER, T. J. "Rewarding Lula: Executive Power, social policy, and the Brazilian elections of 2006". Latin American Politics \& Society, vol. 49, n²1, p. 1-30, 2007.

Licio, E. C.; RenNó, L. R.; CASTRO, H. C. "Bolsa Família e voto na eleição presidencial de 2006: em busca do elo perdido". Opinião Pública, vol. 15, n 1, p. 31-54, jun. 2009.

LóPEZ, M. "The state of poverty: elite perceptions of the poor in Brazil and Uruguay". International Sociology, vol. 28, n 3, p. 351-370, maio 2013.

MARQUES, A. C. S. "O Programa Bolsa-Família na mídia e na fala das beneficiárias: o lugar ocupado pelo Estado na configuração dialógica dos espaços de debate público". Revista ECO-Pós, vol. 11, nº 1,9 nov. 2008.

. "A deliberação a longo prazo no espaço de visibilidade mediada: o Bolsa-Família na mídia impressa e televisiva". Estudos em Jornalismo e Mídia, vol. 7, n² 2, p. 273-285, 21 set. 2010.

MARQUES, R. M., et al. "Discutindo o papel do programa Bolsa Família na decisão das eleições presidenciais brasileiras de 2006". Revista de Economia Política, vol. 29, n 1, p. 114-132, mar. 2009.

Nicolau, J.; Peixoto, V. "As bases municipais da votação de Lula em 2006". In: Cadernos Fórum Nacional, n 6. Rio de Janeiro: Instituto de Altos Estudos, p. 15-25, 2007.

Pereira, C.; Rennó, L.; Samuels, D. Corruption, campaign finance, and reelection. In: Power, T. J.; TAYLOR, M. (eds.). Corruption and democracy in Brazil: the struggle for accountability. Notre Dame: University of Notre Dame Press, p. 80-99, 2011.

REIS, E. Perceptions of poverty and inequality among Brazilian elites. In: REIS, E.; MOORE, M. (eds.). Elite perceptions of poverty and inequality. London/New York: Zed Books, p. 26-56, 2005.

ReIS, E.; MOORE, M. Elites, perceptions and poverties. In: ReIS, E.; MOORE, M. (eds.). Elite perceptions of poverty and inequality. London/New York: Zed Books, p. 1-25, 2005.

RenNó, L. "Escândalos e voto: as eleições presidenciais brasileiras de 2006". Opinião Pública, vol. 13, $n^{\circ} 2$, p. 260-282, 2007. 
Rennó, L.; CABello, A. "As bases do lulismo: a volta do personalismo, realinhamento ideológico ou não alinhamento?". Revista Brasileira de Ciências Sociais, vol. 25, n 74, p. 39-60, 2010.

SHIKIDA, C., et al. "It's the economy, companheiro!: an empirical analysis of Lula's re-election based on municipal data". Economics Bulletin, vol. 29, n² 2, p. 977-992, 2009.

Singer, A. "Raízes sociais e ideológicas do lulismo". Novos Estudos - Cebrap, n 85, p. 83-102, jan. 2009.

SOARES, F. V., et al. "Cash transfer programmes in Brazil: impacts on inequality and poverty". International Poverty Center - UNDP/Ipea, Working Paper, n²1, 2006.

SoARES, G. A. D.; TeRron, S. L. "Dois Lulas: a geografia eleitoral da reeleição (explorando conceitos, métodos e técnicas de análise geoespacial)". Opinião Pública, vol. 14, n² 2, p. 269-301, 2008.

Zucco, C. "The president's 'new' constituency: Lula and the pragmatic vote in Brazil's 2006 presidential elections". Journal of Latin American Studies, vol. 40, n 1, p. 29-49, 2008.

"When pay outs pay off: conditional cash-transfers and voting behavior in Brazil 20022010". American Journal of Political Science, vol. 47, n 3, 2013.

\section{Resumo}

Os custos eleitorais do Bolsa Família: reavaliando seu impacto sobre a eleição presidencial de 2006

O padrão geográfico da flutuação da votação de Lula entre as eleições presidenciais de 2002 e 2006 é um dos mais intrigantes fenômenos políticos da história recente brasileira. Diversos estudos mostram que o programa Bolsa Família aumentou consideravelmente o apoio a Lula entre os pobres, tendo um papel determinante nos resultados da eleição de 2006. Neste artigo, eu demonstro com base em um banco de dados municipais e técnicas de econometria espacial que seu desempenho eleitoral também se associa negativamente à proporção de ricos. Meu argumento é de que o programa explica ambos os efeitos: os pobres responderam às melhorias em suas condições materiais de vida e os ricos aos custos de oportunidade de investimentos públicos que não lhes beneficiaram diretamente.

Palavras-chave: Bolsa Família; eleições; custos eleitorais; econometria espacial; Lula

\section{Abstract}

The electoral costs of "Bolsa Família": reassessing its impact on the 2006 presidential election

The geographic pattern of Lula's vote swings between 2002 and 2006 presidential elections is one of the most intriguing political phenomenon of Brazilian recent history. Several studies show that the program "Bolsa Família" increased considerably Lula's support among the poor, having a crucial role on the 2006 electoral results. In this article, I analyze a municipal-level data set and use spatial econometrics techniques to show that Lula's electoral performance is also negatively associated with the proportion of the rich. My claim is that the program explains both effects: the poor responded to improvements in their material living conditions and the rich responded to opportunity costs of public investments that did not benefit them directly.

Keywords: Bolsa Família; elections; electoral costs; spatial econometrics; Lula 


\section{Resumen}

Los costos electorales del "Bolsa Família": reevaluando su impacto sobre la elección presidencial de 2006

El patrón geográfico de la fluctuación del voto de Lula entre las elecciones presidenciales de 2002 y 2006 es uno de los fenómenos políticos más intrigantes de la historia brasileña reciente. Diversos estudios muestran que el programa "Bolsa Família" aumentó considerablemente el apoyo a Lula entre los pobres, teniendo un papel determinante en los resultados de las elecciones de 2006. En este artículo demuestro, basado en un banco de datos municipales y técnicas de econometría espacial, que su desempeño electoral también se asocia negativamente a la proporción de ricos. Mi argumento es que el programa explica ambos efectos: los pobres respondieron a las mejoras en sus condiciones materiales de vida y los ricos a los costos de oportunidad de inversiones públicas que no los beneficiaron directamente.

Palabras clave: Bolsa Família; elecciones, costos electorales; econometría espacial; Lula

\section{Résumé}

Les coûts électoraux de la "Bolsa Famillia": réévaluation de son impact sur l'élection présidentielle de 2006

Le profil géographique de la fluctuation du vote de Lula entre les élections présidentielles de 2002 et de 2006 est l'un des phénomènes politiques les plus intrigants de l'histoire récente du Brésil. Plusieurs études montrent que le programme "Bolsa Família" a considérablement fait augmenter le soutien des pauvres à Lula, jouant un rôle de premier plan au niveau des résultats des élections de 2006. Dans cet article, je démontre, en me fondant sur une base de données municipale et des techniques économétriques spatiales, que sa performance aux élections est également associée négativement à la proportion de riches. Mon argument est que ce programme explique les deux effets : les pauvres ont répondu à l'amélioration de leurs conditions matérielles de vie et les riches aux coûts d'opportunité d'investissements publics qui ne leur ont pas profité directement.

Mots-clés: Bolsa Família; élections; les coûts électoraux; économétrie spatiale; Lula

Artigo submetido à publicação em agosto de 2014. Versão final aprovada em outubro de 2015. 